\section{AATS Annual Meeting Accreditation}

The American Association for Thoracic Surgery is accredited by the Accreditation Council for Continuing Medical Education to provide continuing medical education for physicians.

The American Association for Thoracic Surgery designates this educational activity for a maximum of $36.5 \boldsymbol{A M A} \boldsymbol{P R A}$ Category 1 Credits. ${ }^{\mathrm{TM}}$ Physicians should only claim credit commensurate with the extent of their participation in the activity.

\section{Aortic Symposium 2010}

\author{
April 29-30, 2010 \\ Sheraton New York Hotel and Towers \\ New York, New York \\ Course Directors \\ Randall B. Griepp, MD \\ Mount Sinai School of Medicine \\ Steven L. Lansman, MD, PhD \\ Westchester Medical Center

\section{Co-Directors} \\ Joseph E. Bavaria, MD \\ University of Pennsylvania \\ Nicholas T. Kouchoukos, MD \\ Missouri Baptist Medical Center \\ David Spielvogel, MD \\ Westchester Medical Center
}

\section{Program Overview}

Aortic Symposium 2010 is a two-day symposium focused on the pathophysiology, diagnosis, and treatment of aortic aneurysms and dissections. The faculty consists of world leaders in this field who have been invited to share their experience regarding difficult problems in aortic disease.

\section{Course Format}

Aortic Symposium 2010 will primarily feature faculty presentations of original work or "state of the art reviews." Manuscripts selected from submitted abstracts will comprise the balance of the program and be considered for publication in a supplement of the Journal of Thoracic and Cardiovascular Surgery.

Accepted presentations will be available on the Presentation on Demand (POD) System, a network of computer stations distributed throughout the meeting area that permits attendees to review PowerPoint presentations on demand.

\section{Registration \& Housing Information}

To register and reserve housing, visit www.aats.org/aortic Housing Deadline: Friday, April 12, 2010

\section{Educational Objectives}

Upon completion of this course, participants will be able to:

- Analyze the natural history, evaluation, imaging, and design a management plan for the treatment of aneurysms involving the ascending, arch, and thoracoabdominal portions of the aorta.

- Identify management strategies for the evaluation, management, and treatment of aortic dissection.

- Implement surgical options for replacing or preserving the aortic valve during aortic root replacement.

- List approaches to cerebral and spinal cord protection during aneurysm surgery.

- Integrate the use of various materials for surgical treatment of aneurysm disease, including collagen impregnated grafts, composite graphs, and homografts.

- Apply endovascular approaches to thoracic aortic aneurysm disease, including hybrid surgical and endovascular procedures.

\section{Target Audience}

This course is designed to meet the educational needs of:

- Cardiovascular and Thoracic surgeons

- Residents and Fellows

- Perfusionists

- ICU and OR Nurses, Physician Assistants and others involved in the care of individuals with aortic disease

\section{Accreditation}

The American Association for Thoracic Surgery is accredited by the Accreditation Council for Continuing Medical Education to provide continuing medical education for physicians.

The American Association for Thoracic Surgery designates this educational activity for a maximum of 13.3 AMA PRA Category 1 Credits. ${ }^{\mathrm{TM}}$ Physicians should only claim credit commensurate with the extent of their participation in the activity.

Visit www.aats.org/aortic to learn more about Aortic Symposium 2010.

\section{AATS Meetings and Sponsored Events}

\section{March}

March 21-26, 2010

15th Annual Update on Cardiopulmonary Bypass*

Fairmont Chateau

Whister, BC, Canada 